Bol. Acad. peru. leng. 61. 2016 (35-46)

\title{
El secreto de la rosa en dos poemas de Sologuren: «Interludio» $\mathbf{y}$ «Rosa terrena»
}

\section{The secret of the rose in two poems of Sologuren: «Interludio» (Interlude) and «Rosa terrena» (Earthly Rosa)}

\author{
JiM ANCHANTE ARIAS \\ Universidad Nacional Mayor de San Marcos \\ Université Bordeaux Montaigne
}

Resumen:

El presente ensayo es un análisis de los poemas «Interludio» (El morador [1944]) y «Rosa terrena» (Diario de Perseo [1948]), incluidos en el libro Vida continua (1989) del poeta peruano Javier Sologuren (1921-2004), poeta perteneciente a la Generación de 1945. Dicho análisis tiene como marco teórico la reflexión sobre el símbolo poético de la rosa, la cual, como sabemos, tiene una larga tradición tanto en el mundo occidental como oriental. Así, en el primer poema la rosa sugiere una reflexión sobre la naturaleza y el tiempo. En el segundo poema, y continuando con la problemática existencial del primero, se pone énfasis en la angustia humana en torno a la vida y la muerte. 


\section{Abstract:}

This essay is an analysis of the poems "Interludio» (El morador [1944; Inhabitant]) and "Rosa terrenal» (Diario de Perseo [1948; Perseus' diary]), included in the book Vida continua (1989; Continuous Life) of the Peruvian poet Javier Sologuren (1921-2004), who belonged to the Generación de 1945 (Generation '45). The theoretical framework of this analysis is the reflection of the poetic symbol of the rose, which, as we know, has one long tradition as in the Western as Oriental world. Thus, as the first poem suggests, the rose is a reflection on nature and time. In the second poem, and continuing with the existential problem of the first, it places most emphasis on the human anguish over the life and death awareness.

Palabras clave: Poesía, rosa, símbolo, tiempo, angustia.

Keywords: Poetry, rose, symbol, time and anguish.

Recibido: 31/01/2016

Aceptado: 29/02/2016

\section{Naturaleza y tiempo: «Interludio»}

En poderes que fluyen puntualmente suavizando los labios de abandono, sensible su semblante aduerme tono ardoroso naranja frutecente.

Del imperio suavísimo corono amoroso sitial, malva ferviente; el anheloso pulso que se siente perece en toda piel, en todo tono. 
Silencio de magnolias ensombrece su personal estar, su rumorosa condición vegetal se nos ofrece en fresca tierra, mundo en que reposa, como campo lunar que palidece, enamorado ser, oscura rosa.

(Sologuren 1989: 24-25)

Este poema corresponde a su primera colección, El morador, publicada en 1944. Por entonces, el poeta tenía veintitrés años. Sin embargo, como ya lo ha señalado buena parte de la crítica, los poemas que conforman el libro presentan una precoz madurez. Por ejemplo, Ana María Gazzolo señala que El morador ya es un libro maduro (1989: 225). Sobre su estilo, Ricardo Silva-Santisteban anota que

El morador [...] se caracteriza no sólo por su apego a las formas clásicas españolas, como la décima o el soneto, sino también por la búsqueda de un estilo y un gran dominio formal que muestran el rigor con el que Sologuren comenzó y continuó escribiendo su poesía posterior. (1998: 19)

Esta búsqueda de un estilo se manifiesta, por ejemplo, en los hipérbatos sologurenianos que se extienden a lo largo de las tres oraciones en que se encuentra dividido el poema (las dos primeras en cada cuarteto, y la tercera en los dos tercetos). Sin embargo, no es nuestra intención profundizar en su peculiar sintaxis poética, sino brindar ciertas luces de su simbólica floral, sobre todo en relación con la rosa. 
Ahora bien, en otro trabajo de Gazzolo sobre el poeta, siempre considerando su primera colección, nos dice la escritora que la voz poética que recorre estos poemas se configura como un observador dentro del:

espacio estrecho de un jardín doméstico, un lugar solitario resguardado del tráfago ciudadano y más o menos cercano a la gran extensión del mar que se abre más allá de sus límites; dicho ámbito de dimensiones intermedias permite el contacto con el mundo natural y propicia tanto la observación de lo menudo y fugaz como la concentración en los propios pensamientos. (1998: 13)

Concordamos con esta lectura, pues son dos, a nuestro parecer, los elementos que estructuran el mundo poético representado en El morador: la flora y la mar. En el poema que nos compete el primer elemento se manifiesta a través de la caracterización de una imagen cuya ambigüedad nos conduce hacia la humanización de la rosa o la metamorfosis floral del hombre.

Pero empecemos por el título. Según el DRAE, interludio es una «breve composición que ejecutaban los organistas entre las estrofas de una coral, y modernamente se ejecuta a modo de intermedio en la música instrumental» ${ }^{1}$. A partir de esta acepción, dos son los aspectos a destacar: el contexto musical y la posición intermedia dentro de una estructura melódica mayor. Sobre lo primero, siguiendo a Silva-Santisteban en su comentario del poema «El morador», pero que se puede extender al texto que nos compete, el «uso magistral de los recursos sonoros del lenguaje» en Sologuren

1 http: / / lema.rae.es/drae/?val=interludio 
se manifiesta, por ejemplo, en la elección de ciertos fonemas cuya relación con los acentos logra una extraña tonalidad (1998: 20). A partir de ello, la musicalidad sologureniana forma parte de su delicado y minucioso trabajo con la palabra. En cuanto a lo segundo, nos podemos preguntar qué carácter intermedio presenta el poema en cuestión. ¿Podríamos aceptar que se alude al carácter unitario de la colección de poemas? Quizá la respuesta se encuentra en el epígrafe del libro, como señala Gazzolo en relación con la voz poética que se extiende a través de los textos:

Su ubicación y condición de clausura está, en cierta forma, resumida en el epígrafe: Dentro en el rosal matar $m^{\prime}$ han [...] apunta [...] a la posibilidad de que el contacto con la naturaleza se dé en el área de un jardín, sospecha que se confirma por las menciones a plantas pequeñas y flores domésticas (rosa, yedra, magnolia); quien habla en estos poemas se encuentra en un ámbito de dimensiones intermedias frente al cual se abre la gran extensión del mar. El morador es, sobre todo, el nombrador de esa morada; si la morada no fuera relevante, el sujeto no se definiría por su relación con ésta. (1989: 225-226)

Pero anotamos que no solo es un jardín, sino un rosal donde la voz pone en riesgo la vida o justamente la desea poner en riesgo. Espacio donde vida y muerte se transfiguran en máscaras opuestas y, justamente por eso, complementarias. En ese sentido podemos entender el carácter intermedio que «Interludio» puede tener dentro del corpus de la colección, muy a pesar de que sea el penúltimo poema, antes del que da título al libro. (O quizá justamente como una presentación, como si este interludio fuera más bien un preludio del 
desenlace, de la voz sintetizadora del morador del universo sologureniano).

La voz poética nos describe, en apariencia, a una persona cuyo sensible semblante expresa un «ardoroso» tono «naranja frutecente». Destaquemos el último adjetivo, neologismo del verbo frutecer y que es sinónimo de fructificar. Ahora bien, el tono de su rostro no es frutecente, sino naranja frutecente (adjetivo de un adjetivo), como si, por ejemplo, en otro contexto podríamos decir que tal objeto manifiesta un color amarillo pálido. Así: naranja que expresa vida y que también la da. En la segunda estrofa, el locutor pasa a una acción a partir de la imagen anteriormente descrita: de este «imperio suavísimo» (lugar y ya no persona), la voz realiza la acción de coronar el «anheloso pulso que se siente». Podríamos corregirnos y aceptar que no es una persona sino un escenario el descrito. Pero con latitud humana, humana y floral a la vez. Y también vida y muerte: el pulso de la vida que "perece en toda piel». Hay un movimiento en que la naturaleza respira y late cual hombre que es coronado, magnificado, por la voz poética en su calidad de rey todopoderoso. Y, en su coronación, destaca lo visto cual «amoroso sitial» y «malva ferviente». Sin embargo, en la tercera parte (últimas dos estrofas) se vuelve a la ambigüedad de si es hombre o planta: se alude a un «silencio de magnolias» que ensombrece su "personal estar» y su «rumorosa condición vegetal», la cual reposa en fresca tierra. Lo ensombrecido de su ser se opone a esta fresca tierra en que yace. Hay, así, un proceso que va de la vitalidad (a través de términos como ardoroso, ferviente y 
anheloso) al acabamiento, a lo ensombrecido y a lo que palidece. Y en el remate poético, dos imágenes que son colocadas en un mismo nivel sintáctico y semántico: el enamorado ser y la oscura rosa. Amor y oscuridad. Existencia y flor. Decimos existencia, pues estamos tratando de entender el nombre «ser» en su sentido más amplio, para no especificarlo y limitar la significación del símbolo sologureniano. Lo que sí nos queda claro, en todo caso, es la lucha de ambivalencias que se oponen en vida-muerte o vitalidad-decadencia, así como la fusión enigmática entre hombre y planta. La rosa, entonces, no solo es oscura por su matiz, sino también por su humanísima condición de estar, muy personal, en el mundo-jardín que empieza con el ardor de la vida y que termina con la sombra y oscuridad de la muerte. Muy aparte del análisis que realiza Javier Ágreda (1998) sobre el tiempo en la poesía de Sologuren, consideramos que en «Interludio» hay cierta linealidad que nos conduce de la vitalidad al ensombrecimiento. Así, la rosa eterna y efímera, bella y mortal, puede simbolizar el acaecer de la vida humana, donde inicio y fin se intercalan como el día y la noche.

\section{La angustia del Yo: «Rosa terrena»}
A solas, en mí mismo, día a día, me hallo lento y dolido penitente; de mí quiero salir, y cuando ausente vierte el amor su púrpura sombría.
(Crece la espina azul de agua reciente, espuma de una efímera alegría en secreto disfrute; melodía del corazón, los labios y la frente.) 
Ya en abandono está lo que se ama, la incesante dulzura de la llama que por húmedo cauce me sostiene.

Soy soledad de ser, de rama y viento, de arena detenida en el momento en que un dorado brazo no se tiene.

(Sologuren 1989: 40-41)

En este poema (que cierra la colección titulada Diario de Perseo [1948]), a pesar de que el nombre del símbolo floral solo es mencionado en el título, la visión que se representa del mismo es, a nuestro parecer, más explícita. A diferencia de «Interludio», en este soneto cada estrofa conforma una oración o unidad sintáctico-significativa. En todas, la voz poética configura un peculiar autorretrato, aunque con matices propios. Por ejemplo, en la primera estrofa el hablante lírico, que gramaticalmente se configura como un "yo» poético, expresa su ensimismamiento cargado de soledad y penitencia, así como un muy dramático «salir en mí» que nos recuerda el malestar existencial nerudiano del «Walking around». Incluso el amor se manifiesta en términos negativos, pues llega a verter su «púrpura sombría».

A continuación, sigue una estrofa que se encuentra entre paréntesis, vale decir, que se relaciona indirectamente con el contenido central del poema, o que quizá nos dice algo más profundo del mismo. El juego metonímico rosa-espina está caracterizado por el color azul, color que, según Chevalier y Gheerbrant en su Diccionario de símbolos (1986: 893) ${ }^{2}$, representa lo impo-

2 La primera edición francesa es de 1969. Para el presente trabajo, usamos la traducción castellana incluida en la bibliografía. 
sible cuando de una rosa se trata. En todo caso, aquí se evidencia con mayor claridad la simbolización de lo bello y lo efímero en la rosa. Su agua es nueva, pero su alegría (o juventud, o belleza) es efímera. La referencia musical se explicita en la metáfora sobre la «melodía del corazón, los labios y la frente». Latido, voz y pensamiento que representan el movimiento acompasado y melódico de la vida. Secreto disfrute. Efímera alegría. El tiempo y sus consecuencias vuelven a cobrar un rol protagónico, a nuestro parecer, en esta imagen de la espina y su doble caracterización de alegría y dolor.

Otro símbolo en que debemos reparar es el agua, que recorre los diferentes momentos del poema y que se suele identificar con la vida y la fertilidad. Como dijimos en la primera estrofa, el amor es como un conducto que vierte un agua funesta, metaforizada en la imagen de la púrpura sombría. Y en esta segunda parte nos encontramos con una espina de agua reciente, así como una espuma de efímera alegría. Hay dos instancias de la vida: alegría y disfrute, pero también sombra y dolor justamente a partir de la condición efímera de lo anterior. Y en la tercera estrofa la noción de amor vuelve a chocar con lo perecedero, pues «Ya en abandono está lo que se ama». A continuación, se establece un escenario antitético al mejor estilo de Quevedo (a quien, por cierto, el poeta tenía en gran estima), cuando se construye la imagen sinestésica de una llama dulce e incesante, la cual sostiene al yo poético por un húmedo cauce. Agua y fuego que vuelven a ser antípodas y a la vez complementarios. Sostén del hombre y fuente de su pérdida, de su abandono y continuidad en un mundo que es él mismo y del que no puede salir. 
En la última estrofa la voz poética completa su ensimismamiento con la soledad, una soledad vegetal en la que el hombre se halla y que no termina. Y aquí sí funciona la visión poética del tiempo sologureniano, cuando Ágreda sostiene que:

[...] el centro cordial de toda la poesía de Sologuren es el propósito de negar el paso del tiempo, de refutar su carácter lineal e irreversible; y que lo que hemos denominado sus ideas corresponde a lo que Habermas define como subjetividad moderna, aquella forma de pensamiento que se caracteriza por su autonomía, por regirse principalmente por la razón y, especialmente, por su capacidad de criticarlo todo, incluso a sí mismo. (1998: 42)

La metonimia de la arena detenida es la del reloj que no avanza, que no parece avanzar ante la pérdida de lo que somos o, en otras palabras, la soledad del ser. El dorado brazo que no se tiene juega con la doble acepción de término: humano y vegetal. En ambos casos estamos ante un miembro que yace en la luz (dorado en tanto sol), mientras que nuestro restante cuerpo yace en la púrpura sombría del amor, del amor que en Sologuren es exaltación, pero también desvelo. Amenaza, goce, destrucción.

En «Rosa terrena», el símbolo de la rosa es el yo poético, el yo ontológico que se busca y no termina de encontrarse. En ese sentido, si en los poemas de El morador el yo se hace vacío, como señala atinadamente Abelardo Oquendo (1968), en los poemas de Diario de Perseo y específicamente en «Rosa terrena», el yo cobra forma. Paradójicamente, forma ambivalente y ambigua. Fragmentos de cuerpo y vegetal que 
se actualizan en el símbolo de la rosa terrena, hecha de carne y pétalo en su dialéctica visión de vida y deterioro.

Para terminar, quisiéramos recordar que en una entrevista realizada en 1980 por Violeta Lubarsky y Reynaldo Jiménez al poeta, que fue publicada en La Opinión de Buenos Aires, se le menciona a Sologuren el pertenecer a una generación de poetas. Sologuren responde afirmativamente y luego observa: «Mi generación es la que ha sucedido a la de Martín Adán y Emilio Adolfo Westphalen...» (2004: 68). Y si bien luego no hay una alusión directa al autor de La casa de cartón, consideramos que la mención no es gratuita, pues la rosa adaniana (representada, curiosamente, también a través del formato del soneto), es también una rosa ontológica, aunque más etérea y metafísica. La rosa sologureniana, al menos en los dos poemas que han sido motivo de nuestro comentario, es más corpórea en el sentido de que no pierde su lado vegetal y gana más bien un lado humano. Pero esa ganancia es paradójica, ya que implica a su vez una pérdida. Y esa pérdida genera una búsqueda del ser que termina siendo, con toda su belleza y estremecimiento, el poema. 


\section{Bibliografía}

ÁGREDA, Javier. «El rosal en el interior del reloj: el tempo en la poesía de Javier Sologuren», en La casa de cartón de OXY. No 14. Lima, 1998, págs. 18-23 y 40-47.

CHEVALIER, Jean y Alain GHEERBRANT. Diccionario de símbolos. Barcelona, Herder, 1986.

EIELSON, Jorge Eduardo. «La pasión según Sologuren», en Lienzo. $\mathrm{N}^{\circ}$ 9. Lima, 1989, págs. 279-289.

GAZZOLO, Ana María. «Javier Sologuren: Poesía, razón de vida», en Lienzo. No 9. Lima, 1989, págs. 219-278. . «La imagen de quien escribe», en La casa de cartón de OXY. No 14. Lima, 1998, págs. 11-17.

GONZÁLEZ VIGIL, Ricardo. «Lectura continua de Sologuren», en Revista Hispanoamericana de Literatura. $\mathrm{N}^{\circ}$ 3. Lima, 2003, págs. 45-58.

JIMÉNEZ, Reynaldo y Violeta LUBARSKY. «Javier Sologuren: la experiencia de la palabra», en Lienzo. No 25. Lima, 2004, págs. 65-86.

OQUENDO, Abelardo. «Sologuren: la poesía y la vida», en Amaru. N$^{\circ}$ 5. Lima, 1968, págs. 56-61.

RAMíREZ, Luis Hernán. Estilo y poesía de Javier Sologuren. Lima, Ediciones de la Biblioteca Universitaria, 1967.

SILVA-SANTISTEBAN, Ricardo. "Vida continua de Javier Sologuren», en La casa de cartón de OXY. No 14. Lima, 1998, págs. 18-23.

SOLOGUREN, Javier. Vida continua. Lima, Colmillo Blanco, 1989. 